\title{
POLÍTICAS DE FINANCIAMENTO DA EDUCAÇÃO NA ARGENTINA, NO URUGUAI E NO BRASIL (1990-2014)*
}

\author{
NALÚ FARENZENA ${ }^{1}$ @ \\ JUCA GIL ${ }^{1} \bullet$ \\ Maria Goreti Farias Machado ${ }^{1}$ (๑) \\ Rosa Maria Pinheiro Mosna ${ }^{1}$ (1)
}

\begin{abstract}
RESUMO: São analisadas políticas de financiamento da educação da Argentina, do Brasil e do Uruguai, abrangendo comparação entre os países e entre um período de governos progressistas (2003-2014) e a década de 1990, quando foram implementadas políticas de corte neoliberal. As políticas são enfocadas em três dimensôes responsabilidades governamentais, gasto público e distribuição de recursos entre governos —, sendo pontuadas situaçóes de manutenção ou redefinição. Evidenciaram-se, em termos gerais, redefiniçóes parciais, bem como a forte influência das formas de Estado e de organizaçáo da educação dos países no financiamento da educação.
\end{abstract}

Palavras-chave: Financiamento da educação. Educação comparada. Educação no Brasil. Educação na Argentina. Educação no Uruguai.

\section{EDUCATION FUNDING POLICIES IN ARGENTINA, URUGUAY AND BRAZIL (1990-2014)}

\begin{abstract}
The education funding policies of Argentina, Brazil and Uruguay are analyzed, contrasting the countries and a period of progressive governments (2003-2014) and the 1990s, when neoliberal policies were established. The policies are approached under three dimensions government accountability, public expenditure and distribution of resources among the governments -, being highlighted maintenance or redefinition situations. In general terms, partial redefinitions were evidenced, as well as the strong influence of distinctive marks in education funding according to the forms of State and the countries' educational organization.
\end{abstract}

Keywords: Education funding. Comparative education. Education in Brazil. Education in Argentina. Education in Uruguay.

\footnotetext{
*Artigo desenvolvido no âmbito do projeto de pesquisa Estudo comparado de políticas públicas educacionais nacionais da Argentina, Brasil e Uruguai (2001-2014) (FARENZENA; BENTANCUR; KRAVETZ, 2013). Projeto financiado pelo Conselho Nacional de Desenvolvimento Científico e Tecnológico (CNPq), edital universal 2013.

${ }^{1}$ Universidade Federal do Rio Grande do Sul, Faculdade de Educação - Porto Alegre (RS), Brasil. E-mails: nalu.farenzena@ufrgs.br; jucagil7@gmail.com; mgoretimachado@gmail.com; rosamosna@gmail.com DOI: $10.1590 / E S 0101-73302018191934$
} 


\title{
Politiques de FINANCEMENT DE L'ÉDUCATION en Argentine, AU BrÉSil ET EN URUGUAY (1990-2014)
}

\begin{abstract}
RÉSUMÉ: Les politiques de financement de l'éducation en Argentine, au Brésil et en Uruguay sont analysées dans cette article, où on couvre une comparaison entre ces pays et entre une période de gouvernements progressistes (2003-2014) et les années 1990 lorsque des politiques néolibérales ont été mises en œuvre. Les politiques sont axées sur trois dimensions - les responsabilités gouvernementales, les dépenses publiques et l'allocation des ressources entre les gouvernements - en mettant l'accent sur de situations de maintenance ou redéfinition. En termes généraux, des redéfinitions partielles ont été mises en évidence, ainsi que la forte influence des formes d'organisation des finances pour l'éducation dans les pays et selon les lignes de l'État.
\end{abstract}

Mots-clés: Financement de l'éducation. Éducation comparée. L'éducation au Brésil. L'éducation en Argentine. L'éducation en Uruguay.

\section{Delimitações iniciais}

A

presentamos, neste artigo, uma análise comparativa de políticas públicas de financiamento da educação, de âmbito nacional e nas etapas anteriores à educação superior, da Argentina, do Brasil e do Uruguai entre os anos 2000 e 2014. Nossa pesquisa abrange três eixos de políticas de financiamento, explorados nas seguintes dimensões: responsabilidades governamentais no financiamento da educação, gasto público e mecanismos de distribuição de recursos entre governos.

A década de 2000 marcou, nos três países, o advento de governos nacionais mais progressistas no continuum esquerda-direita, em contraste com a década de 1990, quando políticas de corte neoliberal pautaram as açôes públicas. Tal movimento foi o mote para o estudo de semelhanças e diferenças entre políticas educacionais da Argentina, do Brasil e do Uruguai.

Os países da América Latina destinavam à educação 4,3\% de seu produto interno bruto (PIB) no ano 2000. Uma década depois, esse percentual acercou-se aos $5 \%{ }^{1}$. Essa evoluçáo foi impulsionada por contextos nacionais e por compromissos internacionais que convocam para maiores investimentos na educação básica, com destaque para a sinalização da Organização das Naçóes Unidas para a Educação, a Ciência e a Cultura (UNESCO, 2005) de investimento num nível de 6\% do PIB.

Na Argentina, a Ley de Financiamiento Educativo, de 2005, fixou a meta de atingir um gasto correspondente a 6\% do PIB até 2010. O aumento de 
recursos foi crescente, tendo sido alcançado 6,2\% do PIB em 2012. Não obstante, esse país, de organização federativa, ainda enfrenta severas diferenças entre os gastos realizados pelas províncias.

No Brasil, o Plano Nacional de Educação 2014-2024² estabeleceu em 7 (até 2019) e 10\% (até 2024) as metas de investimento em educação como proporção do PIB. O gasto público em educação passou de 4 para 5,6\% do PIB em $2010^{3}$. As desigualdades na capacidade de gasto entre estados e municípios, contudo, permanecem marcantes.

No Uruguai, o governo do partido Frente Amplio, iniciado em 2005, cumpriu com seu compromisso programático da campanha eleitoral de elevar o gasto em educação a 4,5\% do PIB, o que requereu expressivo incremento de recursos.

O financiamento da educação é trabalhado no viés de políticas públicas, no sentido de estudo de programas de ação pública, isto é, "dispositivos político-administrativos coordenados em princípio em torno de objetivos explícitos" (MULLER; SUREL, 2002, p. 11). Nesse recorte de dispositivo político-administrativo, condensam-se escolhas delineadas, em grande parte, no cruzamento de referenciais das políticas fiscal e educacional e demarcadas por regras institucionais de organização do Estado e do setor, bem como pelos jogos políticos, com caráter mais amplo e setorial.

Busca-se recompor e comparar linhas mais gerais do financiamento da educação, como política pública, nos três países, tendo em conta as dimensões explicitadas. A ênfase recai nos desenhos das políticas de financiamento da educação básica plasmadas em normas de âmbito nacional, com indicaçóes, quando necessário, de traços institucionais que as balizam.

O texto está organizado em seis seçóes, incluindo esta introdução. Os três tópicos seguintes descrevem características do financiamento da educação em cada país. No penúltimo segmento do texto, são discutidas semelhanças e diferenças com base em uma perspectiva mais geral de análise: manutenção ou redefinição pelo contraste entre o período de governos mais progressistas e o anterior e entre os países. Nos comentários finais, sublinhamos os traços mais marcantes da comparação sobre a política de financiamento da educação nos três países.

\section{Financiamento da educação na Argentina ${ }^{4}$}

A Nación Argentina é uma república federativa, presidencialista e constituída de 23 províncias, além da Cidade Autônoma de Buenos Aires, estas consideradas entes subnacionais de governo 5 .

Em 1983, após um período ditatorial, iniciou-se a recuperação da democracia com eleição presidencial; foram tempos conturbados, em que o governo 
nacional lidou com a pesada carga da ditadura e um processo hiperinflacionário. De 1989 a 1999, Carlos Menem (Partido Justicialista) foi o presidente, em dois mandatos, e foram implementadas, no período, políticas de estabilização e ajuste estrutural radicais, de corte neoliberal.

Entre 1998 e 2002, a Argentina passou por graves crises econômica e política. No topo do poder executivo, houve renúncias e sucessão de presidentes nomeados pelas regras do processo sucessório. Em 2003, assumiu um novo presidente eleito, Néstor Kirchner, do Partido Justicialista, de um grupo opositor ao menemismo. A orientaçáo política chamada kirchnerismo esteve à frente do executivo por três mandatos, com Néstor Kirchner (2003-2007) e Cristina Kirchner (2007-2015, dois mandatos).

Nesses governos, foram introduzidas mudanças em determinados âmbitos institucionais, como justiça e direitos humanos, e foi adotado um agregado de propostas de política econômica, algumas em contradição com as do período anterior, como as do questionamento de acordos com o Fundo Monetário Internacional (FMI), limites para empresas privatizadas e definiçóes em termos de renacionalização de empresas públicas (LOZANO, 2006).

Em 2006, entrou em vigor a Ley de Educación Nacional (LEN), de $\mathrm{n}^{\circ}$ 26.206 (ARGENTINA, 2006a). Durante os governos Menem, foram editadas leis que introduziram transformaçóes na organização do sistema e instituíram um estado avaliador associado à lógica de mercado. A legislaçáo da segunda metade da década de 2000 buscou superar problemas, na direção de afirmar "o papel central do Estado, a prioridade política da igualdade e equidade educativa, a obrigatoriedade da escola secundária" (CARRANZA; KRAVETZ, 2010, p. 40).

A estrutura do ensino compreende a educação inicial (para crianças de 45 dias a 5 anos de idade); a educação primária e a educação secundária, ambas com seis ou sete anos de duração; e a educação superior. A provisão de educação básica pública é realizada pelas províncias, o que é resultado de processos de transferência de responsabilidades do governo nacional para elas. Os níveis de ensino secundário e superior não universitário foram descentralizados no início da década de 1990, situação não alterada nos governos kirchneristas, mas a LEN de 2006 "expresa claramente que el Estado Nacional, los Estados provinciales y la Ciudad de Buenos Aires tienen la 'responsabilidad indelegable' de proveer educación de calidad a todos los habitantes de la Nación" (KRAVETZ, 2014, p. 3). Com efeito, na LEN é estabelecida a corresponsabilidade dos três entes da federação na garantia dos direitos constitucionais de ensinar e aprender, como também da igualdade, gratuidade e equidade.

No que concerne às responsabilidades governamentais no financiamento da educação, cabe assinalar que, na LEN, a educação é reconhecida como bem público, direito individual e social, e é mantida a gratuidade do ensino público. 
A obrigatoriedade escolar, ampliada, abriga crianças de 4 e 5 anos de idade, o primário e o secundário.

A Ley de Financiamiento Educativo preceitua o aumento da aplicação de recursos na educação, ciência e tecnologia, tendo como meta atingir um gasto correspondente a 6\% do PIB. Dos recursos adicionais necessários, os compromissos dos governos nacional e subnacionais devem representar, respectivamente, $40 \mathrm{e}$ 60\%. Para M. Álvarez (2010, p. 30), essa lei “crea nuevas reglas en la coordinación del financiamiento sectorial en los diferentes niveles de gobierno y en cuanto a la utilización de los recursos".

Observa-se que a Ley de Financiamiento Educativo foi a culminância de um processo de luta dos professores, diante da transferência das escolas públicas para as províncias, sem financiamento adequado (YASKI, 2016). Cabe destacar ainda a atuação da Confederación de Trabajadores de la Educación de la República Argentina (CTERA) para que o Estado nacional voltasse a financiar a educação, resultando na criação, em 1998, do Fondo Nacional de Incentivo Docente (FONID).

Por último, compete assinalar que o financiamento público da educação se destina às instituiçóes públicas e às instituiçóes privadas; neste último caso, para garantir que os docentes das instituições privadas tenham remuneração mínima igual aos docentes do setor público.

Quanto ao gasto público em educação, alguns indicadores relevantes estão registrados no Quadro 1, evidenciando-se que, em três deles, as proporçóes aumentaram em 2011. Ou seja, com os governos progressistas, a educação contou com maior volume de recursos. Os dados de 2006 expressam uma situação em que ainda náo haviam sido estabelecidas novas bases para o financiamento da educação.

Nas estatísticas argentinas, encontram-se dados de gasto público em educação por aluno do setor estatal, por província ${ }^{6}$. Fizemos uma sistematização para os anos de 2005 e 2014 ressaltando a manutenção da desigualdade entre as

\section{Quadro 1}

Indicadores de gasto público em educação na Argentina em 2000, 2006 e 2011 (\%).

\begin{tabular}{|l|c|c|c|}
\hline Indicador/ano & $\mathbf{2 0 0 0}$ & $\mathbf{2 0 0 6}$ & $\mathbf{2 0 1 1}$ \\
\hline Gasto em educação/PIB & 4,6 & 3,7 & 5,0 \\
\hline Gasto em educação/gasto das administrações públicas & 16,2 & 16,4 & 16,0 \\
\hline Gasto em educaçáo primária/PIB per capita & 12,4 & 10,3 & 13,5 \\
\hline Gasto em educação secundária/PIB per capita & 15,8 & 14,9 & 19,6 \\
\hline
\end{tabular}

PIB: produto interno bruto.

Fonte: Instituto de Estatísticas da Organização

das Nações Unidas para a Educação, a Ciência e a Cultura (UNESCO). 
províncias no que se refere à capacidade de gasto em educação, mesmo que em 2014 o número de unidades com valores de gasto por aluno em torno de $70 \%$ ou menos da média tenha sido menor. Ainda que haja transferências de recursos do governo nacional visando ao maior equilíbrio, as províncias diferenciam-se acentuadamente nos recursos próprios.

Quanto à remuneração do docente, entre 1995 e 2003 houve aumento da desigualdade salarial entre as províncias. De 2003 em diante, viu-se uma inflexão, pois as províncias passaram a conceder aumentos (ÁLVAREZ, F., 2010). Com efeito, os dados de transferência do governo nacional ao FONID comprovam um incremento significativo. Além disso, a Ley de Financiamiento Educativo previu o estabelecimento de um acordo entre órgãos governamentais e entidades sindicais de docentes do qual, entre outras pautas, constou a melhoria de condiçôes de trabalho, piso salarial e carreira docente.

Dessa forma, o piso salarial estabelecido em $2005^{7}$ para o cargo de maestro de grado, com jornada de quatro horas diárias, foi de 700 pesos, tendo chegado a 1.840 pesos em 2009. Das 24 jurisdiçôes, em 2009, 16 possuíam salário docente acima do piso (ARGENTINA, 2009). As políticas de financiamento implementadas possibilitaram melhorias nos níveis salariais, embora a superação das desigualdades entre as províncias permaneça como desafio.

No que diz respeito a mecanismos de distribuição de recursos entre governos, a Ley de Financiamiento Educativo estabeleceu, pelo prazo de cinco anos, a destinação de recursos de copartição para garantir condiçóes equitativas no sistema educativo nacional. Também criou o Programa Nacional de Compensação Salarial Docente e prorrogou, por cinco anos, o FONID ${ }^{8}$. A norma tinha dupla finalidade: ampliar os recursos destinados à melhoria do sistema educacional e reduzir as diferenças de capacidade de gasto e de salários dos docentes entre as províncias.

Foram definidos critérios de alocação de recursos do governo nacional aos entes subnacionais na coparticipação: a matrícula do nível inicial ao superior não universitário, a incidência relativa da ruralidade na matrícula de educação comum e a proporção de população não escolarizada de 3 a 17 anos. Adicionalmente, a distribuição anual dos recursos do orçamento nacional às províncias e à Cidade Autônoma de Buenos Aires ficou balizada por critérios tais como matrícula, população não escolarizada e capacidade financeira de cada ente? .

\section{Financiamento da educação no Brasil}

Na República Federativa do Brasil, a organização político-administrativa compreende a União, os 26 estados, o Distrito Federal e os municípios, em número de 5.570, em 2014, considerados autônomos nos termos constitucional-legais. 
Entre os anos de 1964 e 1985, o país esteve sob uma ditadura civil-militar. Na redemocratização, gradual, foi promulgada nova Constituição (BRASIL, 1988), em 1988, e ocorreu eleição direta para presidente apenas em 1989, quando assumiu Fernando Collor de Mello, do Partido da Reconstrução Nacional (PRN), em 1990, cujo mandato foi completado pelo vice, Itamar Franco (1992-1994), também do PRN, em função de abertura de processo de impeachment. Em dois mandatos, no período 1995-2002, a presidência coube a Fernando Henrique Cardoso, numa coalizão partidária de centro-direita liderada pelo Partido da Social Democracia Brasileira (PSDB).

Com o governo Collor de Mello, o país sofreu uma guinada liberal, adotando políticas adversas ao nacional-desenvolvimentismo predominante até então. A nova agenda incluiu o tripé de políticas neoliberais: abertura comercial, desregulamentação econômica e privatização do setor produtivo estatal. Segundo Sallum Jr. (2000), reformas implementadas a partir de 1994, no arcabouço constitucional e infraconstitucional do país, solaparam o ordenamento pregresso do Estado nacional-desenvolvimentista. Conforme Castro e Ribeiro (2009), contudo, mesmo com estratégias restritivas do gasto social nos anos 1980 e 90, salvaguardas jurídicas da Constituição de 1988 em políticas sociais protegeram o gasto público na área.

De 2003 a 2014, o Brasil teve na presidência uma coalizão de centro-esquerda liderada pelo Partido dos Trabalhadores (PT), com os seguintes presidentes: Luiz Inácio Lula da Silva (dois mandatos, de 2003 a 2010) e Dilma Rousseff (2011-2014). Mantiveram-se fundamentos da agenda macroeconômica anterior, entretanto, de acordo com Castro et al. (2009), houve redirecionamentos na intervenção estatal na área social em prol da promoção da cidadania. Para Fagnani (2011), houve, entre 2006 e 2010, ensaios desenvolvimentistas, com ampliação do gasto social, para o qual concorreram melhorias no mundo do trabalho e nas contas públicas e certo descrédito da ideologia neoliberal com a crise internacional de 2008.

A estrutura do ensino compreende a educação básica e a educação superior. A educação básica subdivide-se em educação infantil — creche (crianças de 0 a 3 anos de idade) e pré-escola (crianças de 4 e 5 anos de idade) —; ensino fundamental, de nove anos de duração; e ensino médio, com três anos de duração mínima. A provisão de educação escolar é compartilhada pelos três níveis governamentais, com prioridades: municípios devem focar na educação infantil e no ensino fundamental; estados, no ensino fundamental e ensino médio; e a União deve organizar e financiar a rede pública federal de ensino e prestar assistência financeira e técnica aos estados e municípios.

Tratando-se de responsabilidades governamentais no financiamento da educação, cabe assinalar que esta é um dos direitos sociais de cidadania afirmados na Constituição Federal (BRASIL, 1988). Nela, a gratuidade do ensino público 
é posicionada como um dos princípios da educação. A obrigatoriedade escolar foi redefinida em 2009 e abrange a educação básica para a população de 4 a 17 anos de idade.

Dadas as especificidades do federalismo no setor educacional, as três esferas de governo possuem responsabilidades no financiamento da educação, para o qual concorrem definiçōes de prioridades de cada esfera de governo e outras mais gerais. Uma dessas últimas é o ensino obrigatório; outra é a destinação dos recursos públicos ao ensino público, embora seja permitido alocá-los a instituiçōes privadas.

Cabe reiterar que, no Plano Nacional de Educação (PNE) 2014-2024, foram fixadas metas de gasto público em educação como proporção do PIB: 7\% até 2019 e $10 \%$ até 2024, porém permanece como grande desafio definir as fontes de recursos para atingir essas metas e a contribuição de cada esfera de governo nesse esforço.

Dados gerais do gasto público em educação estão registrados no Quadro 2, destacando-se a evolução positiva nos dois intervalos. Em pontos percentuais, sobressai o aumento nos gastos na educação primária e na secundária sobre o PIB per capita.

Com o intuito de ilustrar as diferenças em termos de capacidade de gasto em educação básica nos estados e na falta de dados que consolidem o total gasto, comentaremos valores por aluno, de 2006, do Fundo de Manutenção e Desenvolvimento do Ensino Fundamental e de Valorização do Magistério (FUNDEF), e de 2014, do Fundo de Manutenção e Desenvolvimento da Educação Básica e de Valorização dos Profissionais da Educação (FUNDEB). Em 2006, quando a complementação da União representou apenas 1\% dos recursos do FUNDEF, as diferenças entre os valores mínimos dos estados eram muito acentuadas: por exemplo, dez estados tinham um valor que era mais do que o dobro do mínimo nacional. Em 2014, oitavo ano do FUNDEB, somente um estado registrou valor por aluno maior que $50 \%$ do valor mínimo nacional. A maior equiparação deveuse ao aumento da contribuição da União.

\section{Quadro 2}

Indicadores de gasto público em educação no Brasil em 2000, 2006 e 2011 (\%).

\begin{tabular}{|l|c|c|c|}
\hline Indicador/1no & $\mathbf{2 0 0 0}$ & $\mathbf{2 0 0 6}$ & $\mathbf{2 0 1 1}$ \\
\hline Gasto em educação/PIB & 3,9 & 4,9 & 5,7 \\
\hline Gasto em educação/gasto das administrações públicas & 11,45 & 12,42 & 15,27 \\
\hline Gasto em educaçáo primária/PIB per capita & 10,6 & 15,4 & 20,8 \\
\hline Gasto em educação secundária/PIB per capita & - & 17,9 & 22,6 \\
\hline
\end{tabular}

PIB: produto interno bruto.

Fonte: Instituto de Estatísticas da Organização das

Naçōes Unidas para a Educação, a Ciência e a Cultura (UNESCO). 
Cabe dizer que, do gasto total público em educação, são maiores os esforços dos municípios e estados, considerando sua atuação direta na oferta de educação básica e a apropriação relativamente menor da carga tributária. Por isso, o aumento da participação da União no financiamento público da educação tem feito parte da agenda de políticas públicas nos últimos anos.

Outro marco com impacto nas prioridades e no volume de gastos foi a criação do Piso Salarial Profissional Nacional (PSPN), valor mínimo que os docentes devem receber como vencimento inicial, conforme Lei no 11.738/2008 (BRASIL, 2008). Os valores do PSPN evoluíram positivamente, em termos reais: $\mathrm{R} \$ 1.280,77$ em 2009, $\mathrm{R} \$ 1.398,48$ em 2011 e $\mathrm{R} \$ 1.697,00$ em 2014. Apesar do novo parâmetro legal, entretanto, nem todos os governos subnacionais cumpriram os valores estipulados, o que gera fortes reivindicaçóes, especialmente por parte dos sindicatos docentes.

Quanto a mecanismos de distribuição de recursos entre governos, trataremos da principal política de redistribuição de recursos financeiros na educação, o FUNDEB, cujos objetivos são manter e desenvolver a educação básica e valorizar os profissionais docentes da educação. Tal política passou a vigorar em 2007, em substituição ao FUNDEF e, em relação a este, abrange toda a educação básica, além de ter ampliado a quantidade de fontes de impostos e os percentuais de cada fonte. Ademais, o governo nacional deixou de ter participação financeira incerta, contribuindo de modo permanente e em bases fixas.

O FUNDEB é constituído, de fato, de fundos estaduais compostos de parte significativa dos recursos da receita resultante de impostos dos estados e dos municípios vinculada à manutenção e ao desenvolvimento do ensino $-20 \%$ de diversos itens de receita - e de recursos complementares da União. A repartição dos recursos, feita no âmbito de cada estado, leva em conta as proporçōes de matrículas de cada ente. A complementação da União é a transferência de verbas a fundos estaduais cujos recursos próprios não permitem atingir o valor mínimo nacional por aluno. Portanto, visa equiparar disponibilidades financeiras. $\mathrm{O}$ valor da complementação deve corresponder a, no mínimo, $10 \%$ dos recursos totais de contribuição dos governos estaduais e das prefeituras.

\section{Financiamento da educação no Uruguai ${ }^{10}$}

A República Oriental del Uruguay é um Estado com ordenação institucional unitária, mas com unidades territoriais subnacionais, os departamentos.

Nos anos 1990, com o restabelecimento da institucionalidade democrática, após um período de ditadura civil-militar, foram implementadas reformas inspiradas no Consenso de Washington, visando à reforma do Estado, por meio de estratégias como estabilização macroeconômica, liberalização comercial e financeira, 
privatização e desregulamentação de empresas e serviços públicos, segundo Moreira e Delbono (2010). Conforme essas autoras, contudo, as mudanças ocorridas no Uruguai, e diferentemente de países vizinhos, caracterizaram-se pelo gradualismo e pela heterodoxia; por exemplo, as privatizaçôes não ocorreram em larga escala.

Na primeira metade da década de 1990, o país viveu um ciclo de evoluçáo positiva da economia, seguido de desaceleração, com o que o crescimento se desvinculou da redução da pobreza e a desigualdade aumentou. O partido Frente Amplio assumiu o governo nacional em 2005 com proposta de justiça social, combate à pobreza e promoção da participação social, representando uma virada à esquerda, com rechaço ao paradigma neoliberal (MOREIRA; DELBONO, 2010). Desde 2005, o Frente Amplio está à frente do governo nacional, com os seguintes presidentes: Tabaré Vázquez (2005-2010), José Mujica (2010-2015) e Tabaré Vázquez (mandato 2015-2020).

No ano de 2008, foi editada a Lei no 18.437 - Ley General de Educación (LGE) —, cuja elaboração constou do programa de governo do Frente Amplio e do orçamento quinquenal 2005-2010 (URUGUAI, 2009).

A estrutura da educação formal compreende a educação inicial (crianças de 3 a 5 anos); a educação primária (seis anos de duração); a educaçáo média (seis anos de duração); a educação terciária universitária e a não universitária; e a pósgraduação. A administração da educação básica formal é centralizada, no sentido de que são os órgãos nacionais que têm a responsabilidade de gestáo direta da educação pública. Uma peculiaridade do Uruguai é que, na educação formal não universitária, grande parte das decisóes e açóes político-administrativas é da alçada da Administração Nacional da Educação Pública (ANEP), um órgão com estatuto autonômico. O Ministério da Educação tem reduzidas atribuiçôes se comparado a ministérios similares (BENTANCUR, 2012).

Bentancur e Mancebo (2010), ao tratarem de continuidades e inovações na educação no primeiro governo Vázquez, dizem que, com as reformas do período anterior, se manteve o modelo estadista, centralizado e de financiamento público. As inovaçóes do governo de esquerda deram-se em conformidade com esse modelo e dizem respeito à estratégia procedimental, o que abarca, entre outras medidas, aumento de recursos.

No que concerne às responsabilidades governamentais no financiamento da educação, uma referência é o preceito de gratuidade do ensino público na legislação. A obrigatoriedade escolar foi ampliada em 2008 e abrange a educação inicial para crianças de 4 e 5 anos, a educação primária e a média. Na Ley General de Educación (URUGUAI, 2009), a educação é considerada um direito humano, um bem público e social, e seu art. 14 proíbe a assinatura de tratados internacionais que "directa o indirectamente signifiquen considerar a la educación como un servicio lucrativo o alentar su mercantilización”. 
Cabe reiterar aqui que o governo do Frente Amplio se comprometeu a elevar o gasto em educação a um nível correspondente a 4,5\% do PIB; no orçamento nacional 2005-2009, foi estipulado o aumento gradual de recursos para assegurar a alocação de 4,5\% do PIB à educação pública.

O gasto público em educação, no sistema formal, deve destinar-se à provisão de educação pública ${ }^{11}$. A educação privada não recebe apoio financeiro estatal, a não ser isençóes de tributos e de pagamento de alguns impostos em função de doaçóes de empresas privadas ao setor educacional público ou privado.

De acordo com o Informe sobre el estado de la educación en Uruguay 2014, do Instituto Nacional de Evaluación Educativa (INEE, 2014), o gasto público em educação como percentual do PIB evoluiu de 3,2\%, em 2004, para 4,5\%, em 2009, e 4,8\%, em 2013, em valores reais. Considerando esses mesmos anos, o gasto público representava, respectivamente, 18,6, 25,0 e 28,2\% do gasto do governo central. O gasto público em educação por estudante, como porcentual do PIB per capita, em 2010, foi de 13,5\% na educação primária e 15,4\% na educação média. Em termos de distribuição do gasto, entre os níveis da educação, há maior concentração na educação média, ao que segue, pela ordem, a primária, a terciária e a educação inicial e da primeira infância (Quadro 3).

Segundo De Armas (2010), o aumento de recursos para a educação pública constituiu uma das linhas políticas centrais do primeiro governo de Tabaré Vázquez. Chegar ao gasto equivalente a 4,5\% do PIB requereu passar de 570 milhóes de dólares em 2005 para 1,5 bilhão de dólares em 2009. O mesmo autor explica que o incremento do gasto se concentrou na recuperação dos salários docentes.

O crescimento das remuneraçóes docentes ocorreu com mais força de 2005 em diante, quando foi instaurada negociação coletiva por meio de Conselhos de Salários. Entre 2005 e 2013, o salário dos docentes aumentou em média $61 \%$ em termos reais, aumento superior ao salário médio geral, que cresceu

\section{Quadro 3}

Distribuição do gasto público em educação como porcentagem do gasto do governo central no Uruguai em 2004, 2009 e 2013.

\begin{tabular}{|l|c|c|c|}
\hline Nível/ano & $\mathbf{2 0 0 4}$ & $\mathbf{2 0 0 9}$ & $\mathbf{2 0 1 3}$ \\
\hline Educação inicial e da primeira infância & 1,7 & 2,5 & 3,1 \\
\hline Primária & 5,7 & 7,5 & 7,7 \\
\hline Média & 6,2 & 8,4 & 9,3 \\
\hline Terciária & 4,2 & 5,4 & 5,7 \\
\hline Sem nível & 0,8 & 1,2 & 2,4 \\
\hline
\end{tabular}

Fonte: Instituto Nacional de Evaluación Educativa (INEE, 2014). 
$47 \%$ no mesmo período. Registraram-se incrementos que vão de 52 (docentes do segundo ciclo do médio) a $62 \%$ (docentes de educação inicial e primária). Apesar disso, deve-se considerar que o trabalho docente se desenvolve principalmente em tempo parcial e que são remuneradas as horas/aula, e não outras atividades inerentes à docência; esses são os desafios a se enfrentar na política de trabalho e remuneração docente no Uruguai (INEE, 2016).

\section{Um olhar comparado sobre as políticas de financiamento público da educação}

A análise compreende duas comparaçóes: entre o período de governos progressistas e o precedente, de orientação neoliberal, e entre os três países. As dimensôes foram desdobradas em tópicos, cada qual sendo objeto de um juízo que considera as situaçōes de manutenção, redefiniçẫo e redefinição parcial (Quadro 4).

$\mathrm{Na}$ dimensão responsabilidades governamentais no financiamento da educação, distinguem-se tópicos que repercutem mais diretamente na demanda de ação estatal por estabelecerem balizas para prioridades. A obrigatoriedade escolar foi ampliada nos três países, fato que apresenta repercussóes diretas no financiamento, uma vez que cabe ao Estado universalizar a oferta. A gratuidade do ensino público, já afirmada na legislação dos três países, é mantida. Em termos de destinação dos recursos, há manutenção de regras: na Argentina, a alocação de recursos ao setor privado prioriza a garantia de paridade nos salários docentes; no Brasil, mantêm-se a prioridade de gastos estatais no setor público e a possibilidade de repasses ao setor privado, a qual foi ampliada no período; no Uruguai, os recursos estatais são destinados ao setor público. Quanto à distribuição de responsabilidades entre governos, há mudanças na Argentina e no Brasil. A legislação argentina cria novas regras de responsabilidade e coordenação entre os governos nacional e subnacionais, das quais se destaca a ampliaçáo do compromisso do governo nacional, com critérios mais objetivos. No Brasil, é ampliado o compromisso da Uniáo no financiamento da educação básica. No que concerne a referências-chave para o gasto, há mudanças nos três países, pois foram estabelecidas metas de ampliação do gasto, tendo como sinalizaçáo a proporção do PIB. No Brasil, consideramos esse tópico como de redefiniçâa parcial, pois os objetivos só foram estabelecidos em 2014, na lei do PNE (BRASIL, 2014), além de não terem sido fixados os compromissos de cada esfera de governo na consecução das metas. Já na Argentina, foi detalhada a participação dos entes federativos no esforço para atingir o alvo.

Em relação aos gastos públicos, os dados sinalizam aumento dos percentuais do PIB aplicados em educação nos três países. É notável que Argentina e Brasil tenham estipulado em lei regras com metas para o aumento dos gastos no setor. Havia e ainda há, nesses dois países, expressivas desigualdades regionais no tocante ao gasto por aluno. No caso brasileiro, o FUNDEB reverteu a tendência 
e reduziu as diferenças de recursos disponíveis nos estados. Na Argentina, persistem capacidades de gasto bastante diferenciadas entre as jurisdiçóes, mesmo com os instrumentos de equiparação implementados. No que diz respeito aos salários docentes, pode-se notar que a criação de pisos na Argentina e no Brasil, bem como o estabelecimento de Conselhos de Salários no Uruguai, levou à valorização das

\section{Quadro 4}

Síntese comparativa das dimensóes consideradas em financiamento público da educação na Argentina, no Brasil e no Uruguai.

\begin{tabular}{|c|c|c|c|c|}
\hline Dimensóes & Tópicos & Argentina & Brasil & Uruguai \\
\hline \multirow{5}{*}{$\begin{array}{l}\text { Responsabilidades } \\
\text { governamentais } \\
\text { no financiamento } \\
\text { da educação }\end{array}$} & Obrigatoriedade escolar & Redefinição & Redefinição & Redefinição \\
\hline & $\begin{array}{l}\text { Gratuidade do } \\
\text { ensino público }\end{array}$ & Manutenção & Manutenção & Manutenção \\
\hline & $\begin{array}{c}\text { Destinação dos recursos } \\
\text { públicos ao setor } \\
\text { público ou aos setores } \\
\text { público e privado }\end{array}$ & Manutenção & Manutenção & Manutenção \\
\hline & $\begin{array}{l}\text { Distribuição de } \\
\text { responsabilidades entre } \\
\text { esferas ou instâncias } \\
\text { de governo }\end{array}$ & Redefinição & Redefinição & Manutenção \\
\hline & $\begin{array}{l}\text { Referências para o } \\
\text { gasto em educaçáo }\end{array}$ & Redefinição & $\begin{array}{l}\text { Redefinição } \\
\text { parcial }\end{array}$ & Redefinição \\
\hline \multirow{5}{*}{$\begin{array}{l}\text { Gasto público } \\
\text { em educação }\end{array}$} & \% PIB em educação & $\begin{array}{l}\text { Redefinição } \\
\text { parcial }\end{array}$ & $\begin{array}{l}\text { Redefinição } \\
\text { parcial }\end{array}$ & $\begin{array}{l}\text { Redefinição } \\
\text { parcial }\end{array}$ \\
\hline & $\begin{array}{c}\text { Metas de gasto } \\
\text { em educação }\end{array}$ & Redefinição & Redefinição & $\begin{array}{l}\text { Redefinição } \\
\text { parcial }\end{array}$ \\
\hline & Desigualdades regionais & Manutenção & $\begin{array}{l}\text { Redefinição } \\
\text { parcial }\end{array}$ & - \\
\hline & Salários dos docentes & Redefinição & Redefinição & Redefinição \\
\hline & $\begin{array}{l}\text { Aporte de recursos } \\
\text { públicos para } \\
\text { instituiçóes privadas }\end{array}$ & Manutenção & $\begin{array}{l}\text { Redefinição } \\
\text { parcial }\end{array}$ & Manutenção \\
\hline \multirow{3}{*}{$\begin{array}{l}\text { Mecanismos de } \\
\text { distribuição } \\
\text { de recursos } \\
\text { entre governos }\end{array}$} & $\begin{array}{c}\text { Existência/finalidade } \\
\text { de fundos e outros } \\
\text { mecanismos de } \\
\text { distribuiçáo de recursos }\end{array}$ & Redefinição & Redefinição & - \\
\hline & $\begin{array}{c}\text { Origem dos recursos } \\
\text { dos fundos e outros } \\
\text { mecanismos de } \\
\text { distribuição de recursos }\end{array}$ & Redefinição & Manutenção & - \\
\hline & $\begin{array}{l}\text { Alocação diferencial de } \\
\text { recursos para redução das } \\
\text { desigualdades territoriais }\end{array}$ & Redefinição & Redefinição & - \\
\hline
\end{tabular}

Nota: O travessäo em algumas células indica que o tópico não se aplica ao país; PIB: produto interno bruto. 
remuneraçóes. O Uruguai manteve sua característica de não permitir aporte direto de recursos públicos para escolas privadas. No Brasil, por outro lado, o FUNDEB ampliou a possibilidade já existente de repasse de verbas para instituiçóes não estatais, notadamente para a educação infantil e a educação especial. E na Argentina foi mantida a possibilidade de financiamento público às instituiçóes privadas.

No que tange às características de fundos e outros mecanismos de distribuição de recursos, há algumas semelhanças entre Argentina e Brasil em razão do caráter federativo da organização político-administrativa e da descentralização dos sistemas de ensino e, por conseguinte, muitas diferenças em comparação ao Uruguai, de organização unitária. Tanto no Brasil como na Argentina há a constituição de fundos, embora existam diferenças quanto à finalidade deles. $\mathrm{Na} \mathrm{Ar}$ gentina, o FONID foi instituído, ainda no fim da década de 1990, para melhorar o salário docente, ao passo que no Brasil o FUNDEF (1996-2006) se destinava ao financiamento do ensino fundamental e o FUNDEB (2007 até o momento) abrange a educação básica. Esses dois fundos brasileiros têm pontos de toque com o fundo argentino, pois priorizam a valorização salarial docente. Na Argentina, a redefiniçấo, no período estudado, deveu-se ao estabelecimento de uma política de coparticipação de recursos dos governos nacional e subnacionais e à criação do Programa Nacional de Compensação Salarial Docente.

\section{Considerações finais}

Cabe reiterar que, além da comparação entre os três países, foram examinados dois recortes temporais, em diferentes escalas: é atribuída ênfase ao período que vai de 2000 a 2014, anos de governos progressistas nos três estados, contrastando-o com a década de 1990, quando políticas de corte neoliberal foram adotadas.

Foi realizada, para cada país, uma descrição bastante resumida das particularidades mais marcantes da organização político-administrativa mais geral e da educação, além das conjunturas políticas, como recurso para uma compreensão mais contextualizada das políticas. As três dimensóes consideradas foram desdobradas em tópicos no momento de proceder à análise comparada. Esse foi o construto para discutir traços distintivos e mutaçóes no financiamento das políticas educacionais num período por nós adjetivado de progressista.

A análise comparada das políticas de financiamento da educação básica nos três países sinaliza, numa perspectiva geral, redefiniçóes parciais, ressalvando-se as particularidades de continuidades e mudanças evidenciadas nas dimensóes e nos tópicos e em cada país. Os gastos em educação apresentaram crescimento, assim como foram estabelecidas metas de aumento do nível desse gasto, sobressaindo, nesse contexto, a prioridade dada à elevação dos salários docentes e, na Argentina e no Brasil, a busca de maior equiparação entre as remunerações dos 
professores vinculados a distintas redes públicas de ensino. Nos dois países federativos, houve prorrogação, redefinição ou instituição de instrumentos para minimizar as desigualdades territoriais na capacidade de gasto, mantendo-se, no entanto, assimetrias que comprometem a igualdade na oferta educacional. Deve-se realçar ainda a manutenção, na Argentina e no Brasil, da destinação de recursos públicos ao setor privado como ação continuada, e não apenas episódica.

As formas de Estado - unitária ou federativa - dos três países delimitam as responsabilidades governamentais na oferta e no financiamento da educação. No Uruguai, à organização unitária do Estado corresponde a centralização do setor educacional, com um padrão bastante uniforme de gasto e de padróes de oferta educacional. Nas duas federaçôes, Brasil e Argentina, a distribuição de responsabilidades entre os entes federativos no financiamento e na oferta de educação não são os mesmos, mas, em ambas, as pactuações interfederativas são desafios permanentes com vistas à equiparação nas capacidades de gastos dos governos subnacionais. Nesse marco, uma questão-chave, ainda indefinida, é a efetividade do papel redistributivo dos governos nacionais.

Nossa pesquisa abrangeu, basicamente, análise documental - de legislação e estatísticas - complementada por aportes de produção acadêmica e técnica. Grande parte do material sistematizado diz respeito a preceitos normativos ou dados de recursos aplicados em educação. Com esse corpus, foi possível chegar a resultados que, de nosso ponto de vista, são relevantes e inéditos diante do conhecimento já construído sobre as políticas de financiamento da educação dos anos 2000 e 2010 , tendo em conta as balizas da pesquisa comparativa que apresentamos.

Nossa percepção é de que, juntamente com a análise em si das políticas de financiamento público da educação no Uruguai, no Brasil e na Argentina, construímos uma metodologia ajustada aos objetivos, à comparação que foi projetada e à compreensão do financiamento da educação como política pública.

\section{Notas}

1. Conforme Instituto de Estatísticas da Organização das Nações Unidas para a Educação, a Ciência e a Cultura (UNESCO), World Education Indicators (WEI).

2. O PNE vigente de 2001 a 2011 não continha meta, pois a que fora fixada pela lei aprovada no Congresso Nacional (7\% do PIB) sofreu veto presidencial.

3. Conforme Instituto Nacional de Estudos e Pesquisas Educacionais Anísio Teixeira (INEP)/ Ministério da Educação — Investimento Direto em Educação.

4. Além das referências citadas, a Constituição argentina vigente (ARGENTINA, 1994) foi subsídio para a pesquisa. 
5. Existem também municípios cujas autonomias devem ser delimitadas nas constituiçóes das províncias.

6. De acordo com Dirección de Planeamiento Educativo del Ministerio de Educación y Desporto. Disponível em: < https://www.argentina.gob.ar/educacion/planeamiento/gasto-en-educacion-por-nivel-y-por-objeto> [link Gasto Educativo Provincial. Años 2001-2016-Descargar]. Acesso em: 20 fev. 2018.

7. O estabelecimento do piso salarial é realizado anualmente por meio da Paritária Nacional Docente, com a participação de representantes do Estado nacional, dos governos provinciais e dos sindicatos de docentes. Esse valor serve de referência para os governos subnacionais e para a suplementaçáo de recursos do governo nacional.

8. O FONID foi prorrogado diversas vezes e estava vigente em 2017.

9. Entende-se que esse preceito é de caráter permanente. Portanto, não diz respeito ao programa transitório de copartipação de recursos.

10. Além das referências citadas, a Constituiçẫo uruguaia vigente (URUGUAI, 1967) foi subsídio para a pesquisa.

11. A educação da primeira infância (para crianças de 0 a 3 anos), provida nos Centros de Atenção à Infância e à Família (CAIF), é diferente, pois há prestação de serviço por parte de instituiçôes privadas com financiamento público.

\section{Referências}

ÁLVAREZ, F. Evolución de los salarios docentes en las dos últimas décadas. Entrelíneas de la Política Económica, Argentina, ano 4, n. 25, jun. 2010.

ÁLVAREZ, M. Financiamiento de la educación, debates pendientes. Voces en el Fénix, Buenos Aires, n. 3, p. 30-34, set. 2010.

ARGENTINA. Constitución de la Nación Argentina, de 22 de agosto de 1994. Boletín Oficial, Buenos Aires, 23 ago. 1994.

Ley no 26.206, de 2006. Ley de Educación Nacional. Boletín Oficial, Buenos Aires, 20 dez. 2006a.

- Ministerio de Educación. Coordinación General de Estudio de Costos del Sistema Educativo. Informe Indicativo de Salarios Docentes. Buenos Aires, 2009.

BENTANCUR, N. Aporte para una topografía de las políticas educativas en Uruguay: instituciones, ideas y actores. Revista Uruguaya de Ciencia Política, Montevidéu, v. 21, n. 1, p. 65-92, jan./jun. 2012.

BENTANCUR, N.; MANCEBO, M. E. El discreto encanto del gradualismo. Continuidad, restauración e innovación en las políticas educativas del primer gobierno de izquierda. In: MANCEBO, M. E.; NARBONDO, P. (Orgs.). Reforma del Estado y politicas públicas de la Administración Vázquez: acumulaciones, conflictos y desafíos. Montevidéu: Fin de Siglo Editorial, 2010. p. 248-265. 
BRASIL. Constituição da República Federativa do Brasil, de 05 de outubro de 1988. Diário Oficial da União, Brasília, 05 out. 1988. p. 1.

Lei no 11.738 , de 16 de julho de 2008. Institui o piso salarial profissional nacional para os profissionais do magistério público da educação básica. Diário Oficial da União, Brasília, 2008.

Lei no 13.005 , de 13 de junho de 2014. Aprova o Plano Nacional de Educação. Diário Oficial da União, Brasília, 2014.

CARranZA, A.; KRAVETZ, S. Políticas Públicas y Educación Secundaria. Políticas Educativas, Porto Alegre, v. 3, n. 2, p. 40-55, 2010.

CASTRO, J. A. de; RIBEIRO, J. A. C. As políticas sociais e a Constituição de 1988: conquistas e desafios. In: Políticas Sociais: acompanhamento e análise. Brasília: IPEA, 2009. v. 1. n. 17. p. 17-97. (Número especial: Vinte Anos da Constituição Federal).

CASTRO, J. A. de; RIBEIRO, J. A.; CAMPOS, A. G.; MATIJASCIC, M. A CF de 88 e as políticas sociais brasileiras. In: CARDOSO JR., J. C. (Org.). A Constituição brasileira de 1988 revisitada: recuperação histórica e desafios atuais das políticas públicas nas áreas econômica e social. Brasília: IPEA, 2009. v. 1. p. 55-122.

DE ARMAS, G. Políticas sociales y gasto público social en el primer gobierno del Frente Amplio: "el descubrimiento de la infancia". In: MANCEBO, M. E.; NARBONDO, P. (Orgs.). Reforma del Estado y políticas públicas de la Administración Vázquez: acumulaciones, conflictos y desafíos. Montevidéu: Fin de Siglo Editorial, 2010. p. 224-247.

FAGNANI, E. A política social do governo Lula (2003-2010): perspectiva histórica. SER Social, Brasília, v. 13, n. 28, p. 41-80, jan./jun. 2011.

FARENZENA, Nalú; BENTANCUR, Nicolás; KRAVETZ, Silvia. Estudo Comparado de Políticas Públicas Educacionais Nacionais da Argentina, Brasil e Uruguai (20012014). Porto Alegre: UFRGS, 2013. 28 f. Projeto de Pesquisa - Faculdade de Educação, Universidade Federal do Rio Grande do Sul, Porto Alegre, 2013.

INSTITUTO NACIONAL DE EVALUACIÓN EDUCATIVA (INEE). Informe sobre el estado de la educación en Uruguay 2014. Montevidéu: INEE, 2014.

Los salarios docentes en Uruguay (2005-2014). Montevidéu: INEE, 2016.

KRAVETZ, S. El sistema educativo en Argentina: aportes para el proyecto trinacional Argentina-Brasil-Uruguay. Córdoba, 2014.

LOZANO, C. Argentina. In: ELIAS, A. (Org.). Los Gobiernos Progresistas en Debate. Buenos Aires: CLACSO, 2006.

MOREIRA, C.; DELBONO, A. De la era neoliberal a la reemergencia de la "cuestión social”. In: MANCEBO, M. E.; NARBONDO, P. (Orgs.). Reforma del Estado y politicas públicas de la Administración Vázquez: acumulaciones, conflictos y desafíos. Montevidéu: Fin de Siglo Editorial, 2010. p. 97-114.

MULLER, P.; SUREL, Y. Análise das políticas públicas. Pelotas: EDUCAT, 2002. 
ORGANIZAÇÃO DAS NAÇÓES UNIDAS PARA A EDUCAÇÃO, A CIÊNCIA E A CULTURA (UNESCO). Educación para Todos: el imperativo de la calidad. Informe de Seguimiento de la Educación para Todos 2005. Paris: UNESCO, 2005.

SALLUM JR., B. Globalização e desenvolvimento: a estratégia brasileira nos anos 90 . Novos Estudos CEBRAP, São Paulo, n. 58, p. 131-156, nov. 2000.

URUGUAI. Constitución de la República Oriental del Uruguay, de 15 de febrero de 1967 [con las modificaciones plebiscitadas el 26 de noviembre de 1989, el 26 de noviembre de 1994, el 8 de diciembre de 1996 y el 31 de octubre de 2004]. Montevidéu, 1967.

. Ley no 18.437 de 2009. Ley General de Educación. Diario Oficial, Montevidéu, n. $27654,2009$.

YASKI, H. Financiamiento educativo: una lucha histórica de la CTERA. In: CONFEDERACIÓN DE TRABAJADORES DE LA EDUCACIÓN DE LA REPÚBLICA ARGENTINA (CTERA). Porque defendemos la Educación Pública de calidad reclamamos una nueva Ley de Financiamiento Educativo. Buenos Aires: Ediciones CTERA, 2016. p. 6-9. (Serie Pedagogía y Políticas Educativas).

Recebido em 21 de fevereiro de 2018.

Aceito em 11 de julho de 2018. 